\title{
MOULD AND WINTER INDOOR RELATIVE HUMIDITY IN LOW INCOME HOUSEHOLDS IN ENGLAND
}

\author{
Tadj Oreszczyn ${ }^{1}$, lan Ridley ${ }^{1}$, Sung H. Hong ${ }^{1}$, Paul Wilkinson ${ }^{2}$, \\ and the Warm Front Study Group ${ }^{2,3}$
}

I - Bartlett School of Graduate Studies, University College London

2 - Public \& Environmental Health research Unit, London School of Hygiene \& Tropical Medicine 3 - Centre for Regional, Economic and Social Research (CRESR), Sheffield Hallam University

Last updated: 8 August 2006

Words

Abstract: $\quad 176$

Body of text $\quad 2,703$

Address for correspondence: Professor Tadj Oreszczyn, The Bartlett School of Graduate Studies (Torrington Place Site), Gower Street, London WCIE 6BT.

E-mail: t.oreszczyn@ucl.ac.uk, Tel: +44 (0)20 7679 5906, Fax: +44 (0)20 79 I6 I887. 


\section{ABSTRACT}

This paper examines the extent to which variation in heating-season indoor relative humidity and mould occurrence in English households is explained by dwelling and household characteristics. It is based on analysis of data from a national study of England's Home Energy Efficiency scheme (Warm Front) which provides grants for energy efficiency improvements to vulnerable households. Surveys were undertaken of dwellings and households participating in the scheme in five urban areas. Halfhourly living room and main bedroom temperatures and relative humidity measurements were recorded for two to four weeks in a subset of dwellings (I.604) over the winters of 200I-02 and 2002-03. For each dwelling, regression of indoor vapour pressure excess on outdoor temperature was used to obtain estimates of daily living room and bedroom indoor vapour pressure under standardized conditions (outdoor temperature of $5{ }^{\circ} \mathrm{C}$ and $80 \%$ relative humidity), from which standardized values of indoor relative humidity were derived. We present evidence on the relationship between mould severity and standardized relative humidity, and between both these parameters and household and dwelling characteristics, including Warm Front improvements.

Keywords: indoor relative humidity, mould, determinants 


\section{INTRODUCTION}

Poor hygrothermal conditions in houses are recognised to present potential risks to health,[1] [2] with a possible link between low temperatures and excess winter death,[3] [4] [5] [6] and between high relative humidity and respiratory and allergic disease.[7] [8] Two key moisture-related hazards are fungal growth and house dust mites.[7] [9]

Relative humidity $(\mathrm{RH})$ of indoor air is determined by its temperature and moisture content, the latter in turn being a function of the moisture content of the external air, the rate of internal moisture generation, and the dwelling's ventilation rate and volume. Detailed measurements of indoor relative humidity and mould in low income households have recently been obtained from a national evaluation of England's Home Energy Efficiency scheme, known as Warm Front. This scheme, which is targeted at vulnerable households, provides grants for the improvement of home insulation and heating to tackle fuel poverty 'to ensure that the most vulnerable households need no longer risk ill-health due to a cold home'.[10] The national evaluation therefore provides valuable evidence about relative humidity and mould in homes which are among those most likely to be adversely affected by them.

In this paper, we present a first analysis of hygrothermal measurements from this evaluation, and assess the impact of Warm Front interventions on moisture-related parameters. 


\section{METHODS}

The study included 3,099 dwellings undergoing Warm Front improvements over the winters of 200I02 and 2002-03 in five urban areas of England: Birmingham, Liverpool, Manchester, Newcastle and Southampton. These dwellings underwent a property survey, and had detailed measurements of temperature and relative humidity $(\mathrm{n}=1,604)$. In 2,917 households, a computer assisted personal interview was undertaken with a household member.

\section{Standardized internal relative humidity}

Temperature and relative humidity measurements were made by placing Gemini TinyTag data loggers in the main living room and in the main bedroom of dwellings. They were placed away from direct sources of heat and light on a sideboard or shelf at around waist height (approximately one metre from the ground). Measurements of temperature and relative humidity were recorded in both rooms at half-hourly intervals for periods of two to four weeks, yielding on average around a thousand data points per dwelling. Measurements of external temperatures and relative humidity were also recorded in central locations in each of the survey areas. Analysis of indoor temperature and relative humidity was restricted to the I,095 dwellings where recordings were made during periods of cold (i.e. when the maximum daily temperature was less than seven degrees Celsius on at least one day).

To ensure comparability of relative humidity measurements taken during periods of different outdoor conditions, we computed standardized estimates using the following steps. First a standardized living room temperature and bedroom temperature was derived for each dwelling by regression of the indoor on outdoor temperature, as described elsewhere. [II] For this we used data from across the full 24 hour cycle and standardized to 5 degree Celsius outside temperature.

The hourly vapour pressure excess (VPX) - the difference between internal and external vapour pressure - was calculated for the living room and bedroom of each property based on the monitored relative humidity. The indoor vapour pressure excess was regressed on outdoor temperature using 
quadratic terms to allow for non-linearity of the relationship. From the resulting dwelling-specific regression equation, we derived the predicted indoor vapour pressure excess and its standard error at $5^{\circ} \mathrm{C}$ outdoor temperature. The standardized indoor vapour pressure was then estimated by adding the predicted indoor vapour pressure excess at $5^{\circ} \mathrm{C}$ external temperature to the standard external vapour pressure of $690 \mathrm{~Pa}\left(5^{\circ} \mathrm{C}\right.$ external temperature and $80 \%$ external relative humidity).

The standard vapour pressure was then converted to relative humidity based on the standardized living room and bedroom temperatures. It is this quantity, which we refer to as the standardized internal relative humidity, that is the main parameter of air moisture analysed in this paper.

Energy Efficiency: Standard Assessment Procedure (SAP)

Energy efficiency was classified on the basis of the Standard Assessment Procedure (SAP) rating.[12] The SAP is the standard energy calculation of the UK dwellings and is calculated for all new dwellings as part of the Building Regulations and will be the method for England to comply with the European Buildings Directive. The SAP is a measure of the space and hot water heating cost normalized for floor area, assuming a standard heating pattern and fixed on a logarithmic scale resulting in a SAP ranging between 0 and 120 . The heating cost is calculated using a modified degree day method to take account of incidental gains. The average SAP rating of a English dwelling in $200 \mathrm{I}$ is estimated as $5 \mathrm{I}$ and a new dwelling built to the 200I Building Regulations has a SAP of around 75.[13]

Mould Severity Index (MSI)

Each property underwent a detailed visual inspection on the occurrence and extent of mould on windows, walls and ceilings. The species of mould was not however identified. The mould condition in each dwelling was quantified as Mould Severity Index (MSI) - equation I - described in the I996 English House Condition Survey [14]. The mould condition is classified as "slight" for MSI range of I to 2, "moderate" for 3 to 4 and "severe" for 5 and over. Equation I indicates that a dwelling will have an MSI of at least one if there is any mould growth in a single room. 
$M S I=$ the number of rooms with mould growth

$+I$ if there is mould in either living room

$+I$ if the medium mould photograph is identified

+2 if the worst mould photograph is identified

The calculation of MSI requires the quantification of the number of rooms with mould and a comparison of the mould severity against standard photographs showing three classes of mould severity ranging from slight, medium to worst. If mould is found in any living rooms, this is considered to be a greater problem than if it is found in any other room since the living room is generally better heated than the rest of the dwelling.

\section{Air Infiltration Rate}

A fan pressurization method was used to measure the whole house air infiltration rate in a subset of 191 dwellings. Information on the ventilation equipment such as passive and active vents was gathered including the number of open flues and chimneys [15].

\section{Other data}

In addition to the temperature, relative humidity and property data, a number of variables relating to the household and home were collected from interview with a representative of the household (usually the head of household). From this source we used variables relating to the household composition (size and age of oldest family member), as well as self-reported difficulty paying bills, and satisfaction with the heating system. We also used the seven-digit postcode of residence to link each dwelling to its Super Output Area (SOAs are very small areas devised for reporting of census data).[16] For each SOA we obtained the 2004 Index of Multiple Deprivation (IMD) as a measure of socio-economic status. The IMD is based on six area-based parameters: income; employment; health \& disability; education, skills training; housing; and geographical access to services.[17] 


\section{Statistical analysis}

Standardized relative humidity and mould severity index were examined in relation to the dwelling and household characteristics by tabulation and regression methods. Multi-variable analysis of the determinants of mould was carried out by logistic regression using a binary classification in which an MSI score >I was taken as the adverse outcome (a score which excludes the lower range of the "slight" mould classification). The logistic model provides odds ratios which may be interpreted as the relative risk compared to a baseline group of having an MSI score greater than one. In broad terms, they indicate how many times more likely an MSI score $>I$ is at one level of an explanatory variable compared with the baseline level.

Graphs of mould in relation to standardized relative humidity, and of humidity and mould in relation to SAP rating, were generated using a truncated power basis for a natural cubic spline of the relevant explanatory factor. These were generated using Stata's spbase command,[18] with three internal knots for curves with standardized relative humidity as the explanatory factor, and two internals knots for curves with SAP rating as the explanatory factor.

\section{RESULTS}

The median standardized living room relative humidity was $42.8 \%$ (5th centile $32.3 \%$, $95 \%$ centile $59.8 \%$ ) and the median standardized bedroom relative humidity $49.2 \%$ (5th centile 34.8\%, 95th centile $66.3 \%$ ) for the 1.095 dwellings for which the normalised $\mathrm{RH}$ was calculated. Overall, $10.1 \%$ of the surveyed dwellings had a mould severity score greater than one (pre-intervention: $12.2 \%$, postintervention: 7.9\%). For reference, the median standardized living room temperature was $19.1^{\circ} \mathrm{C}$ (5th to 95th centile range: 13.5 to $23.0^{\circ} \mathrm{C}$ ) and the median standardized bedroom temperature $17.1^{\circ} \mathrm{C}$ (5th to 95 th centile range: 12.1 to $21.8^{\circ} \mathrm{C}$ ). However, the living room standardized temperature is based on the daytime hours of $8 \mathrm{am}$ to $8 \mathrm{pm}$ and the bedroom standardized temperature is based on the night-time hours of $8 \mathrm{pm}$ to $8 \mathrm{am}[\mathrm{II}]$. 
The English House Condition Survey 1996, which is the last survey that collected mould or condensation data, reports $14.6 \%$ of the total English stock to have mould growth of any MSI range [14]. In comparison, both the pre-intervention and the post-intervention Warm Front dwellings showed a higher proportion of $22.5 \%$ and $17.1 \%$ respectively. Of the Warm Front dwellings with mould growth, $72.8 \%$ was in the MSI range of I to 2 (pre-intervention: 7I.I\%, post-intervention: 75.2\%), 17.0\% between 3 to 4 (pre-intervention: $18.6 \%$, post-intervention: $14.7 \%$ ) and $10.2 \%$ in the range of 5 and over (pre-intervention: 10.3\%, post-intervention: $10.1 \%$ ). In comparison, the national distribution shows $66 \%$ in the MSI range of I to $2,24 \%$ between 3 to 4 and $10 \%$ in the range of 5 and over [14].

\section{Determinants of relative humidity and mould}

Variation in standardized values of living room and bedroom relative humidity $(\mathrm{RH})$ are shown in Table I. The standardized values for the bedroom are several percent higher than those for the living room, and the variation in relation to each explanatory factor is also generally greater for the bedroom. Although there was only modest variation in $\mathrm{RH}$ in relation to dwelling type and wall fabric, there was a clear and strong gradient with property age (the standardized $\mathrm{RH}$ was lower by several percent in post 1930 dwellings), and a very strong gradient with SAP rating, the more energy efficient dwellings having substantially lower $\mathrm{RH}$ values. Dwellings with $100+\mathrm{mm}$ of roof insulation also had lower RH. Warm Front interventions appeared to be associated with lower $\mathrm{RH}$ in both the living room and the bedroom, with an apparent gradient that heating + insulation measures were associated with lower $\mathrm{RH}$ values than heating alone which in turn was associated with lower values than insulation alone.

Among household characteristics, there was no clear pattern of $\mathrm{RH}$ with socio-economic deprivation, as reflected by the OPDM index of multiple deprivation. However, the standardized RH increased with increasing household number, perhaps reflecting increased level of moisture generation. The largest change occurring from 2 to 3 occupants. Households with a member over 
the age of 60 years also had lower $\mathrm{RH}$, while those reporting dissatisfaction with heating or difficulty in paying bills had significantly higher $\mathrm{RH}$ values.

The pattern of results for the presence of mould broadly parallels that for high standardized relative humidity (Table 2). Having a mould severity score greater than one was less likely in dwellings built within the last 70 years, in homes with $100+\mathrm{mm}$ of roof insulation, and substantially less in energy efficient dwellings with a SAP score over 70. Warm Front interventions were also associated with lower risk of having significant mould, though the gradient with increasing interventions was less clear than for standardized relative humidity.

There was some evidence that households from more deprived areas had higher risk of having an MSI greater than one, and again evidence for higher risk in larger households, and in households reporting difficulty paying bills or with heating the home. Households containing at least one member over 60 years had generally lower risk of an MSI greater than one.

Mould in relation to relative humidity and energy efficiency

Figure I and Table 2 show the clear relationship between standardized relative humidity and the presence of mould. A very small risk of mould was seen even in dwellings with standardized relative humidity below 40 percent, but above this there was a clear gradient of increasing risk, reaching, at $80 \%$ standardized $\mathrm{RH}$, around $40 \%$ risk of having an MSI greater than one.

Standardized relative humidity values and mould risk increased with decreasing SAP rating (Figure 2). There was some evidence that the risk of mould increased fastest at SAP ratings lower than 20, though confidence intervals are consistent with a more-or-less constant (straight line) gradient. The observed pattern from our data is broadly similar to that observed for all dwellings surveyed in the 1996 English House Condition Survey[14] (see Appendix Figure AI).

Warm Front interventions 
The Warm Front energy efficiency program is provided in the form of grants for the installation of cavity wall insulation, loft insulation, draught proofing and depending on the householder's qualification for the scheme, the option of gas wall convector heaters or a gas central heating system. Table 3 provides further elaboration of the results in Tables I \& 2 suggesting that the Warm Front improvements were associated with reductions in indoor relative humidity and risk of mould. The association was clear in analyses adjusted for year, area, socio-economic deprivation and household size. Moreover, there was a strong gradient of lower $\mathrm{RH}$ in homes with more extensive Warm Front improvements; the gradient in mould risk was also apparent but less clear than for RH. Additional adjustment for SAP rating weakened but did not abolish the association between Warm Front improvement and $\mathrm{RH} /$ mould risk, suggesting that some but not all of the change in these parameters can be explained by improvement in energy efficiency.

Internal excess vapor pressure in relation to external temperature

Figure A2 shows a rise in internal concentration of moisture (vapor pressure excess) with decreasing outside temperature based on the Warm Front data. Two factors are thought to explain this. Firstly occupants ventilate their house more during warmer weather and secondly less moisture is produced internally during warmer weather because people dry clothes outside and spend more time outside. BS 5250 [19] categorises dwellings with low occupancy into humidity class of 3 with vapor pressure excess of $610 \mathrm{~Pa}$ at $5^{\circ} \mathrm{C}$. The estimated average vapor pressure excess of the Warm Front dwellings, on the other hand, is much lower at $293 \mathrm{~Pa}$ at $5^{\circ} \mathrm{C}$ based on the regression equation of figure A2. Dwelling air-tightness which is one of the contributing elements to reduced internal moisture level does not explain the low vapor pressure excess of the Warm Front dwellings because the average air infiltration rate of the Warm Front dwellings was 12.9 ach @ 50 Pa which is similar to the UK average of I3.I ach @ 50 Pa [20].

\section{DISCUSSION}


The measurements analysed for this paper represent one of the most comprehensive sets of dwelling-related humidity and mould data for English homes, and the results provide valuable insights into the dwelling and household characteristics that determine mould risk. They have evident bearing on housing standards and regulation for health and safety.[2I]

Our analyses demonstrate a clear relationship between standardized $\mathrm{RH}$ and mould growth, and it should be possible to utilize this evidence along with the measured vapor pressure excess at a particular external temperature to predict the risk of mould growth in any dwelling. Thus, such data are potentially useful in specifying a clear performance standard to avoid mould growth and they may be useful in helping to specify appropriate levels of heating and ventilation required to avoid mould growth as required by the ventilation (Part F) Building Regulations.[22]

The evidence of our analyses is that the risk of mould growth increases above values of standardized relative humidity of around $45 \%$. Laboratory measurements, however, have demonstrated that mould grows when wall surface relative humidity is above $80 \%$ for a period of several weeks [23], although some moulds will grow at relative humidity's as low as 70\% [24]. Because external wall surfaces are normally colder than the internal air, the relative humidity at the surface of an outside wall will be higher than in the bulk of the room air which was monitored for this study. It is generally believed that the most common mould species will not grow on external walls without any thermal bridges provided the internal (air) relative humidity is maintained below $70 \%$ which generally results in a surface relative humidity below $80 \%$. But in buildings, the relative humidity is continually fluctuating because of changes in internal temperature, moisture production (showering, cooking, clothes drying, etc.), external vapor pressure, ventilation (both occupant-controlled and natural due to changes in wind speed and temperature difference between inside and out) and moisture entering or exiting the fabric. Translating the results of simple steady state laboratory measurements into field data is therefore complex.

The principal reason why mould growth appears at a lower standardized relative humidity in this study than the normally accepted $70 \%$ is attributable to the standardization of $\mathrm{RH}$ measurements. We standardized RH to an outdoor temperature of 5 degrees Celsius, which is lower than the 
heating season average. At lower external temperatures, the outdoor air holds less moisture to bring into the building, so the corresponding (indoor) standardized relative humidity appears low. However, the often higher external temperatures, particularly during the damp autumn period, result in higher internal vapor pressures and thus higher relative humidity values at other periods of the year. For instance, the normalization graph shown in figure A2 suggests that a different external condition of $12^{\circ} \mathrm{C}$ and $100 \% \mathrm{RH}$ (damp autumn period) will result in an internal condition of $72 \%$ when the internal temperature is maintained at $19^{\circ} \mathrm{C}$. Thus our standardized $\mathrm{RH}$ corresponds to higher actual RH measurements at other times, and the finding of mould growth at standardized $\mathrm{RH}$ above $45 \%$ does not contradict the current guidance. The fact that a small proportion of homes appear to have mould even at very low standardized RH is most likely to be attributable to mould occurring in localized areas of micro-climate such as on thermal bridges or behind furniture where lower temperatures result in a significant difference between the monitored air and surface relative humidity or where there are localized sources of moisture such as around bed headboards where people exhale.

Of the various dwelling parameters analysed, the most important for high humidity and the second most important - after moisture production (i.e. number of occupants, clothes drying, etc) - for mould growth appears to be energy efficiency, as reflected by the SAP rating. The improvement in SAP explains some, though not all, of the apparent benefit of Warm Front improvements. Improved effectiveness of the heating system, the opening up of living space with the introduction of central heating systems, and the behavioural changes following Warm Front improvements, may all make additional contributions to the reduction in $\mathrm{RH}$ and mould risk.

Most of the reduction in standardized relative humidity from Warm Front interventions occurs because of the increase in temperature, and there appears to be little change in internal vapour pressure from changes in air-tightness. Theoretically the introduction of cavity insulation and draught stripping, which Warm Front improvements often include, could reduce air infiltration. But pressure tests suggest that this reduction is generally offset by an increase in air infiltration associated 
with the installation of central heating systems, particularly when the pipe work feeding radiators is installed below timber floors. [15]

It is worth noting that it is not only dwelling characteristics that determine humidity levels and mould growth. Of particular note from our analyses is the observed increase in risk of mould associated with the number of dwelling occupants which is consistent with the finding of the 1996 English House Condition Survey [14]. The increase in moisture production and vapour pressure excess is associated with higher occupancy levels, and it suggests that the impact of higher occupant density producing more moisture into a given volume is not controlled by higher levels of occupantcontrolled ventilation. Future research will examine the extent that conventional moisture generation algorithms [19] based on occupancy data collected as part of the Warm Front study and ventilation algorithms determined from pressure test results [15] can explain the variation in vapour pressure excess and hence standardized $\mathrm{RH}$.

In conclusion, this study provides quantitative evidence about the principal determinants of indoor relative humidity and mould in low income dwellings in England. Energy efficiency appears to be a particularly important factor, and improvements in it explain part of the clear benefits associated with Warm Front interventions. 


\section{ACKNOWLEDGEMENTS}

This study was undertaken as part of the national evaluation of the Warm Front Scheme (England's

home energy efficiency scheme). It was supported by the Department of the Environment Food and

Rural Affairs (Defra) and the Welsh Assembly Government under contract with the Energy Saving

Trust (EST contract number M47). The views expressed in this paper are those of the authors and

not necessarily those of the funding departments. Paul Wilkinson is supported by a Public Health

Career Scientist Award (NHS Executive, CCB/BS/PHCSO3I).

\section{Conflicts of interest}

None. 


\section{Members of the Warm Front Study Group were}

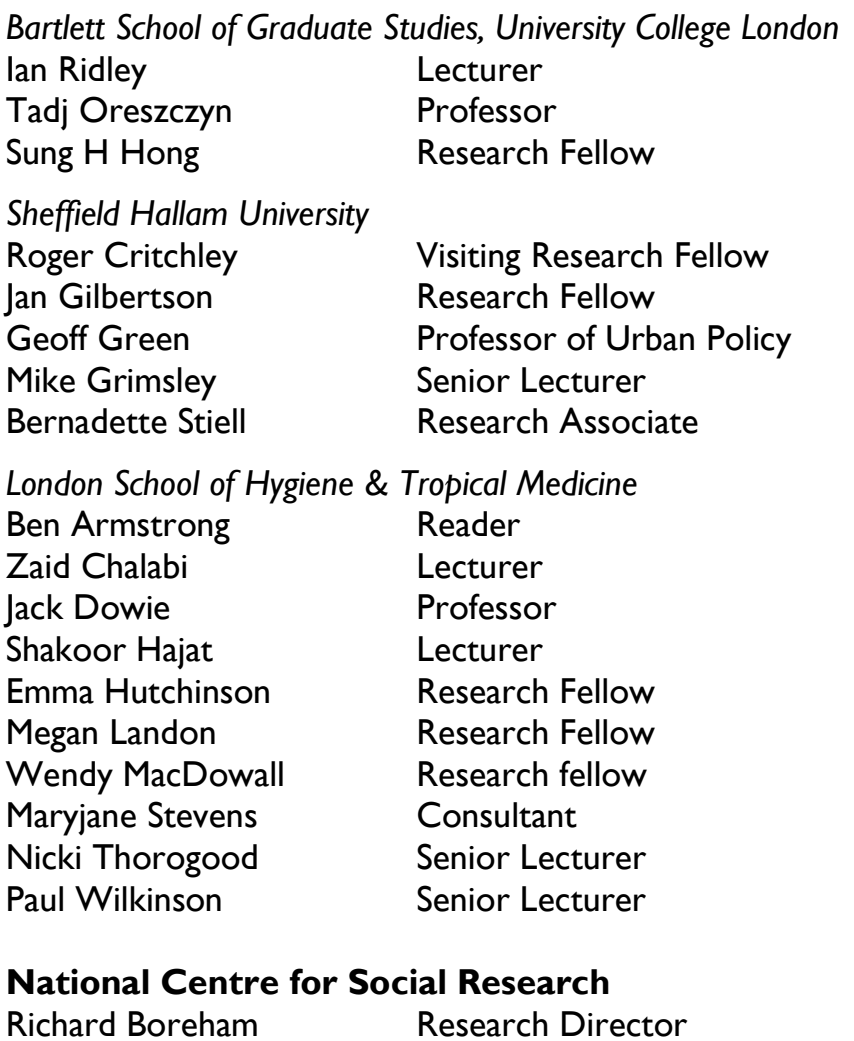




\section{REFERENCES}

[I] Raw G, Aizlewood C, Hamilton M. Building Regulation, Health and Safety. Garston: BRE; 2001.

[2] BMA. Housing and health: building for the future. London: BMA; 2003.

[3] BS EN ISO 13788. Hygrothermal performance of building components and building elements. Internal surface temperature to avoid critical surface humidity and interstitial condensationcalculation methods; 2002.

[4] Mercer JB. Cold--an underrated risk factor for health. Environ Res 2003;92(I):8-13.

[5] Healy JD. Excess winter mortality in Europe: a cross country analysis identifying key risk factors. J Epidemiol Community Health 2003;57(10):784-789.

[6] Wilkinson P, Landon M, Armstrong B, Stevenson S, McKee M. Cold comfort: the social and environmental determinants of excess winter death in England, 1986-1996. York: Joseph Rowntree Foundation; 200I.

[7] Bornehag CG, Sundell J, Bonini S, Custovic A, Malmberg P, Skerfving S, et al. Dampness in buildings as a risk factor for health effects, EUROEXPO: a multidisciplinary review of the literature (1998-2000) on dampness and mite exposure in buildings and health effects. Indoor Air 2004; 14(4):243-257.

[8] Peat JK, Dickerson J, Li J. Effects of damp and mould in the home on respiratory health: a review of the literature. Allergy 1998;53(2): 120-8.

[9] Davies M, Ucci M, McCarthy M, Oreszczyn T, Ridley I, Mumovic D, et al. A review of evidence linking ventilation rates in dwellings and respiratory health: a focus on house dust mites and mould. IJV submitted. 
[10] Department of Trade and Industry. UK Fuel Poverty Strategy. London: DTI; 200 I. http://www.saveenergy.co.uk/index.cfm?page $=05000000$.

[II] Wilkinson P, Oreszczyn T, Sung H. Hong and the Warm Front Study Group. Determinants of Winter Indoor Temperatures in Low Income Households in England. Energy \& Buildings submitted.

[12] BRECSU (on behalf of DEFRA). The Government's Standard Assessment Procedure for Energy Rating of Dwellings 200I EDITION version 9.70. Garston, Watford: BRE; 200 I.

[13] Shorrock L, Utley J. Domestic energy fact file 2003 (BR 457). Watford: BRE; 2003.

[14] English House Condition Survey 1996. Energy Report. London: The Stationery Office; 2000.

[15] Sung H Hong, Ridley I, Oreszczyn T. and the Warm Front Study Group, The impact of energy efficient refurbishment on the air tightness in English dwellings. In: 25th Air Infiltration and Ventilation Centre Conference: Ventilation and Retrofitting; 2004; Prague Czech Republic; 2004. p. 7-I2.

[16] Martin D. Geography for the 200I Census in England and Wales. Population Trends 2002; 108:7-15.

[17] ODPM. Index of multiple deprivation. London: ODPM; 200I.http://www.gowm.gov.uk/regionallntelligence/deprivation

[18] Sasieni P. Natural cubic splines. Stata Technical Bulletin 2003;24 snp7_I.

[19] British Standard 5250:2002, Code of practice for control of condensation in buildings, BSi 2002.

[20] Stephen, R.K., Air tightness in UK dwellings: BRE's test results and their significance, BRE, 1998. 
[21] ODPM. Statistical evidence to support the housing health \& safety rating system. Vols I-3: Project report, Summary of results \& Technical appendix. London: Office of the Deputy Prime Minister;

2003.http://www.odpm.gov.uk/stellent/groups/odpm_housing/documents/page/odpm_house_ 608622.pdf.

[22] ODPM. The Building Regulations Approved Document Part F: Ventilation,. London; 1995 edition, amended 2000.

http://www.odpm.gov.uk/stellent/groups/odpm_buildreg/documents/page/odpm_breg_60047 6.pdf.

[23] Oreszczyn T, Pretlove S. Condensation Targeter II: modelling surface relative humidity to predict mould growth in dwellings. Building Serv Res Technol 1999;20/3:143-153.

[24] Pasanen AL, et al. Fungal growth and survival in building materials under fluctuating moisture and temperature conditions. International Biodeterioration and Biodegradation. 46, 2000, $117-127$. 
Table I. Standardized relative humidity by dwelling and household characteristics.

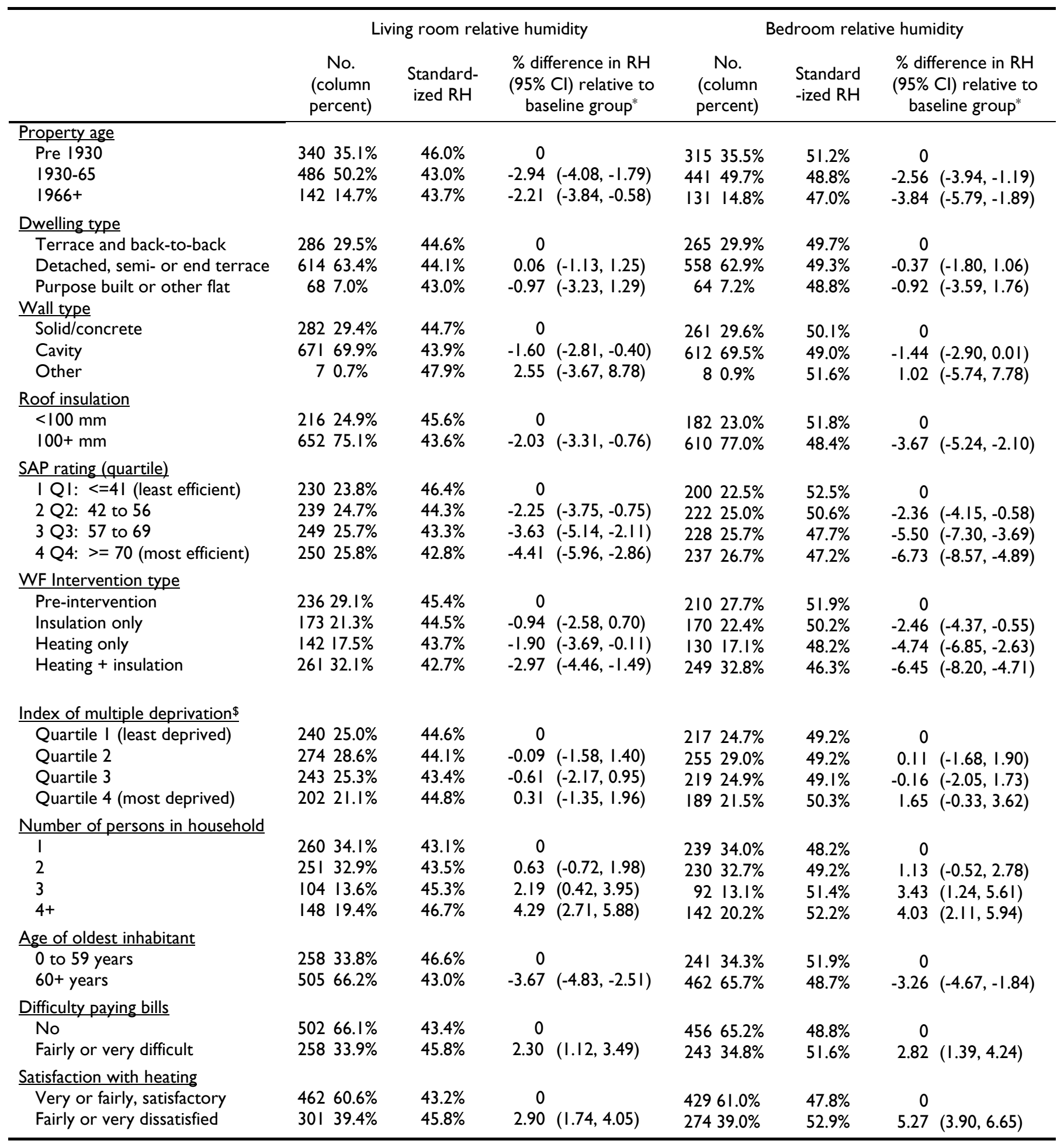

* - Adjusted for year and region

$\$$ - IMD for the Super Output Area of residence 
Table 2. Percent of dwellings with mould severity index $>\mid$ by dwelling and household characteristics.

\begin{tabular}{|c|c|c|c|c|c|}
\hline \multirow[b]{2}{*}{ Property age } & $\begin{array}{l}\text { No. (column } \\
\text { percent) }\end{array}$ & \multirow[t]{2}{*}{$\begin{array}{c}\text { Percent } \\
\text { with mould } \\
\text { severity } \\
\text { index }>1\end{array}$} & \multicolumn{2}{|c|}{$\begin{array}{l}\text { Odds ratios }(95 \% \mathrm{Cl}) \\
\text { relative to baseline group* }\end{array}$} & \multirow[t]{2}{*}{$\begin{array}{l}\text { P-value } \\
\text { for trend }\end{array}$} \\
\hline & & & & & \\
\hline Pre 1930 & $117538.0 \%$ & $11.4 \%$ & I & & \\
\hline $1930-65$ & | $46447.3 \%$ & $9.2 \%$ & 0.64 & $(0.49,0.83)$ & 0.003 \\
\hline $1966+$ & $456 \quad 14.7 \%$ & $9.9 \%$ & 0.66 & $(0.46,0.96)$ & \\
\hline \multicolumn{6}{|l|}{ Dwelling type } \\
\hline Terrace and back-to-back & $95931.0 \%$ & $9.8 \%$ & 1 & & \multirow{3}{*}{0.52} \\
\hline Detached, semi- or end terrace & $192362.2 \%$ & $9.6 \%$ & 0.76 & $(0.58,1.01)$ & \\
\hline Purpose built or other flat & $2106.8 \%$ & $16.2 \%$ & 1.80 & $(1.14,2.85)$ & \\
\hline \multicolumn{6}{|l|}{ Wall type } \\
\hline Solid/concrete & $103333.8 \%$ & $13.2 \%$ & I & & \multirow{3}{*}{$<0.001$} \\
\hline Cavity & $199465.2 \%$ & $8.3 \%$ & 0.52 & $(0.40,0.68)$ & \\
\hline Other & $321.0 \%$ & $21.9 \%$ & 1.09 & $(0.44,2.72)$ & \\
\hline \multicolumn{6}{|l|}{ Roof insulation } \\
\hline$<100 \mathrm{~mm}$ & $69025.5 \%$ & $11.6 \%$ & I & & \multirow[b]{2}{*}{0.005} \\
\hline $100+\mathrm{mm}$ & $201874.5 \%$ & $8.9 \%$ & 0.66 & $(0.49,0.88)$ & \\
\hline \multicolumn{6}{|l|}{ SAP rating (quartile) } \\
\hline | QI: <=4I (least efficient) & $77825.1 \%$ & $13.5 \%$ & I & & \multirow{4}{*}{$<0.001$} \\
\hline 2 Q2: 42 to 56 & $80926.1 \%$ & $9.9 \%$ & 0.67 & $(0.49,0.93)$ & \\
\hline 3 Q3: 57 to 69 & $79425.6 \%$ & $9.9 \%$ & 0.63 & $(0.45,0.88)$ & \\
\hline 4 Q4: >= 70 (most efficient) & $71823.2 \%$ & $6.8 \%$ & 0.35 & $(0.23,0.51)$ & \\
\hline \multicolumn{6}{|l|}{ Normalized relative humidity $^{2}$} \\
\hline I Quartile I (lowest) & $24325.1 \%$ & $5.8 \%$ & I & & \multirow{4}{*}{$<0.001$} \\
\hline 2 Quartile 2 & $24225.0 \%$ & $5.8 \%$ & 0.95 & $(0.44,2.06)$ & \\
\hline 3 Quartile 3 & $24 I \quad 24.9 \%$ & $8.7 \%$ & 1.58 & $(0.77,3.26)$ & \\
\hline 4 Quartile 4 (highest) & $24225.0 \%$ & $16.1 \%$ & 3.57 & $(1.84,6.94)$ & \\
\hline \multicolumn{6}{|l|}{ WF Intervention type } \\
\hline Pre-intervention & $77529.3 \%$ & $12.0 \%$ & I & & \multirow{4}{*}{0.003} \\
\hline Insulation only & $56821.5 \%$ & $9.9 \%$ & 0.68 & $(0.47,0.98)$ & \\
\hline Heating only & $47 \mid 17.8 \%$ & $8.3 \%$ & 0.54 & $(0.36,0.82)$ & \\
\hline Heating + insulation & $83231.4 \%$ & $8.2 \%$ & 0.61 & $(0.43,0.85)$ & \\
\hline \multicolumn{6}{|l|}{ Index of multiple deprivation $\$$} \\
\hline Quartile I (least deprived) & $79125.8 \%$ & $9.9 \%$ & I & & \multirow{4}{*}{0.03} \\
\hline Quartile 2 & $77025.1 \%$ & $11.7 \%$ & 1.79 & $(1.26,2.56)$ & \\
\hline Quartile 3 & $76324.9 \%$ & $10.7 \%$ & 1.65 & $(1.13,2.41)$ & \\
\hline Quartile 4 (most deprived) & $74524.3 \%$ & $8.2 \%$ & 1.68 & $(1.11,2.55)$ & \\
\hline \multicolumn{6}{|l|}{ Number of persons in household } \\
\hline 1 & $82232.5 \%$ & $6.3 \%$ & I & & \multirow{4}{*}{$<0.001$} \\
\hline 2 & $82032.4 \%$ & $9.8 \%$ & 1.69 & $(1.16,2.46)$ & \\
\hline 3 & $352 \quad 13.9 \%$ & $10.5 \%$ & 1.89 & $(1.20,2.98)$ & \\
\hline $4+$ & $53921.3 \%$ & $16.3 \%$ & 3.01 & $(2.06,4.40)$ & \\
\hline Age of oldest inhabitant & & & & & \\
\hline 0 to 59 years & $97038.3 \%$ & $13.3 \%$ & I & & \\
\hline $60+$ years & $156361.7 \%$ & $8.2 \%$ & 0.58 & $(0.44,0.76)$ & $<0.001$ \\
\hline Difficulty paying bills & & & & & \\
\hline No & $156862.1 \%$ & $7.6 \%$ & I & & \\
\hline Fairly or very difficult & $95637.9 \%$ & $14.4 \%$ & 2.20 & $(1.68,2.89)$ & $<0.001$ \\
\hline Satisfaction with heating & & & & & \\
\hline Very or fairly, satisfactory & $146357.8 \%$ & $7.8 \%$ & I & & \\
\hline Fairly or very dissatisfied & $106942.2 \%$ & $13.4 \%$ & 2.05 & $(1.55,2.70)$ & $<0.001$ \\
\hline
\end{tabular}


Table 3. Standardized relative humidity and mould severity index $>I$ in relation to intervention status

\begin{tabular}{|c|c|c|c|c|c|c|c|}
\hline \multirow{2}{*}{ Adjusted for } & \multirow{2}{*}{ Type of intervention } & \multicolumn{4}{|c|}{$\begin{array}{l}\text { Percent difference }(95 \% \mathrm{Cl}) \text { from baseline group } \\
\text { in standardized relative humidity }\end{array}$} & \multirow{2}{*}{\multicolumn{2}{|c|}{$\begin{array}{l}\text { Odds ratios }(95 \% \mathrm{Cl}) \text { for } \\
\text { mould severity index }>1 \\
\text { relative to baseline group } \\
\qquad(\mathrm{n}=2,155)^{*}\end{array}$}} \\
\hline & & & $\begin{array}{l}\text { ng room } \\
=601)^{*}\end{array}$ & & $\begin{array}{l}\text { Bedroom } \\
(\mathrm{n}=640)^{*}\end{array}$ & & \\
\hline $\begin{array}{l}\text { Area, year, } \\
\text { deprivation, } \\
\text { household size } \\
\text { (model I) }\end{array}$ & $\begin{array}{l}\text { Pre-intervention } \\
\text { Insulation only } \\
\text { Heating only } \\
\text { Heating + insulation }\end{array}$ & $\begin{array}{r}0 \\
-1.12 \\
-2.63 \\
-3.41\end{array}$ & $\begin{array}{l}(-3.01,0.78) \\
(-4.46,-0.80) \\
(-4.94,-1.89)\end{array}$ & $\begin{array}{r}0 \\
-2.88 \\
-5.84 \\
-7.62\end{array}$ & $\begin{array}{l}(-5.13,-0.64) \\
(-8.04,-3.64) \\
(-9.44,-5.80)\end{array}$ & $\begin{array}{r}1 \\
0.64 \\
0.47 \\
0.55\end{array}$ & $\begin{array}{l}(0.4 I, I .00) \\
(0.30,0.75) \\
(0.38,0.8 I)\end{array}$ \\
\hline $\begin{array}{l}\text { Model I + } \\
\text { SAP rating } \\
\text { (model } 2)\end{array}$ & $\begin{array}{l}\text { Pre-intervention } \\
\text { Insulation only } \\
\text { Heating only } \\
\text { Heating + insulation }\end{array}$ & $\begin{array}{r}0 \\
-0.51 \\
-1.22 \\
-1.93\end{array}$ & $\begin{array}{l}(-2.43,1.41) \\
(-3.22,0.79) \\
(-3.71,-0.15)\end{array}$ & $\begin{array}{r}0 \\
-2.22 \\
-4.02 \\
-5.63\end{array}$ & $\begin{array}{l}(-4.49,0.05) \\
(-6.43,-1.61) \\
(-7.75,-3.52)\end{array}$ & $\begin{array}{r}1 \\
0.69 \\
0.66 \\
0.81\end{array}$ & $\begin{array}{l}(0.44,1.08) \\
(0.40,1.10) \\
(0.53,1.24)\end{array}$ \\
\hline
\end{tabular}

* all results based on the subset of records with complete data for: area, year, index of multiple deprivation, household size, SAP energy efficiency rating

${ }^{a}$ loft insulation or cavity wall insulation or loft and cavity wall insulation

${ }^{b}$ gas central heating system 
Figure I. Relationship between mould and standardized relative humidity: (A) living room standardized $\mathrm{RH}$, (B) bedroom standardized RH. Graphs show predicted values (solid line) and $95 \%$ confidence intervals (dashed).

(A)

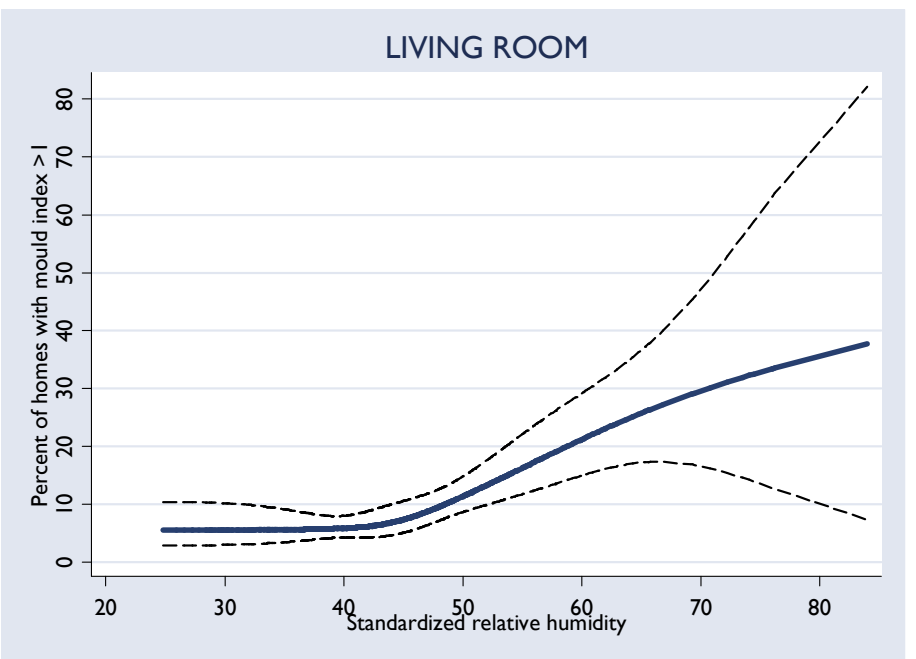

(B)

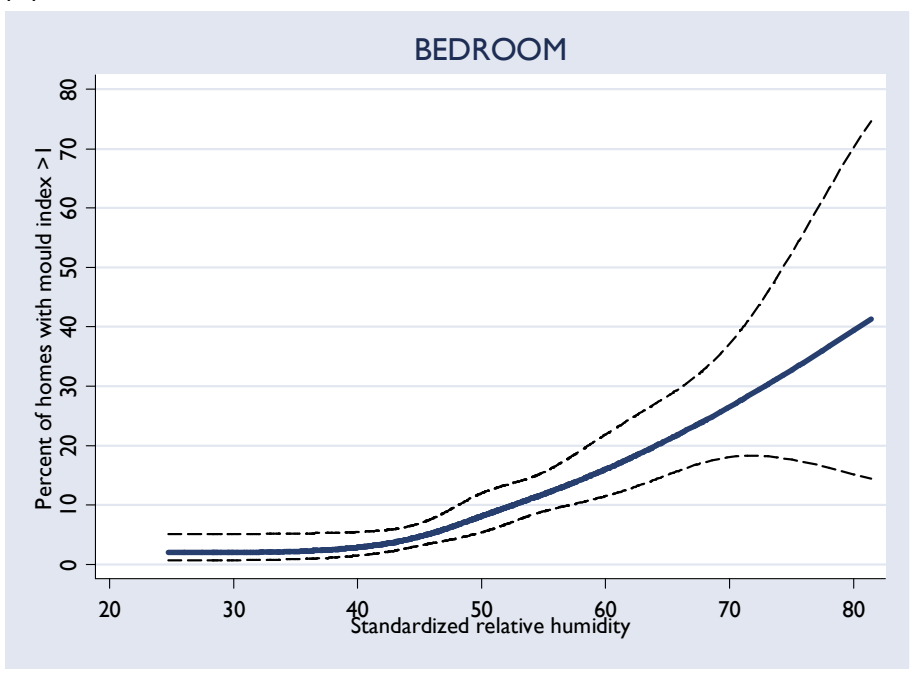


Figure 2. Standardized relative humidity of (A) living room and (B) bedroom against SAP rating; and (C) proportion of homes with mould severity index $>$ I against SAP rating. Graphs show predicted values (solid line) and $95 \%$ confidence intervals (dashed).

(A)

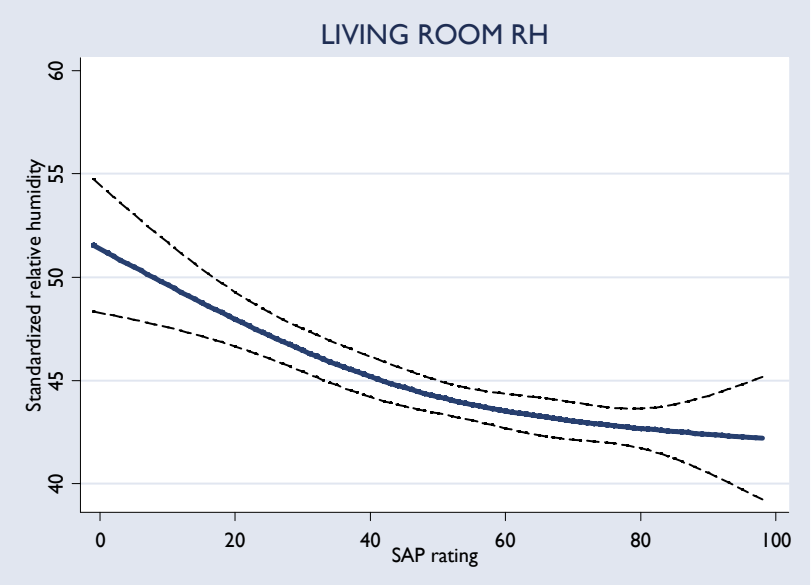

(B)

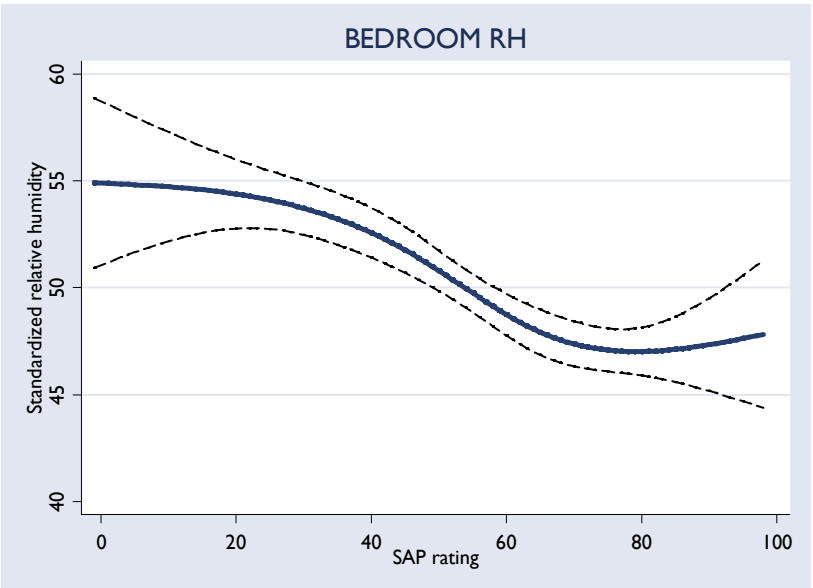

(C) 


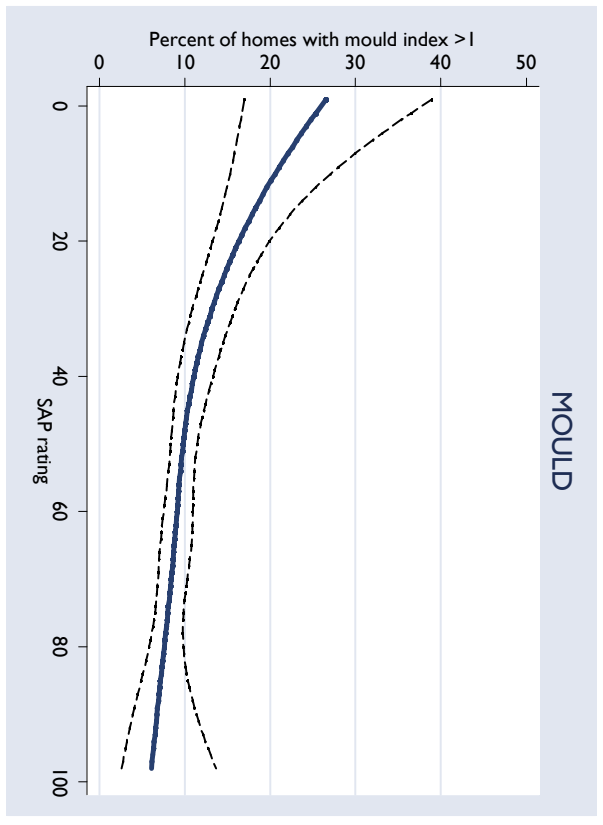




\section{APPENDIX}

Figure AI. Percent Households with mould vs SAP rating. Source: 1996 English House Conditions Survey

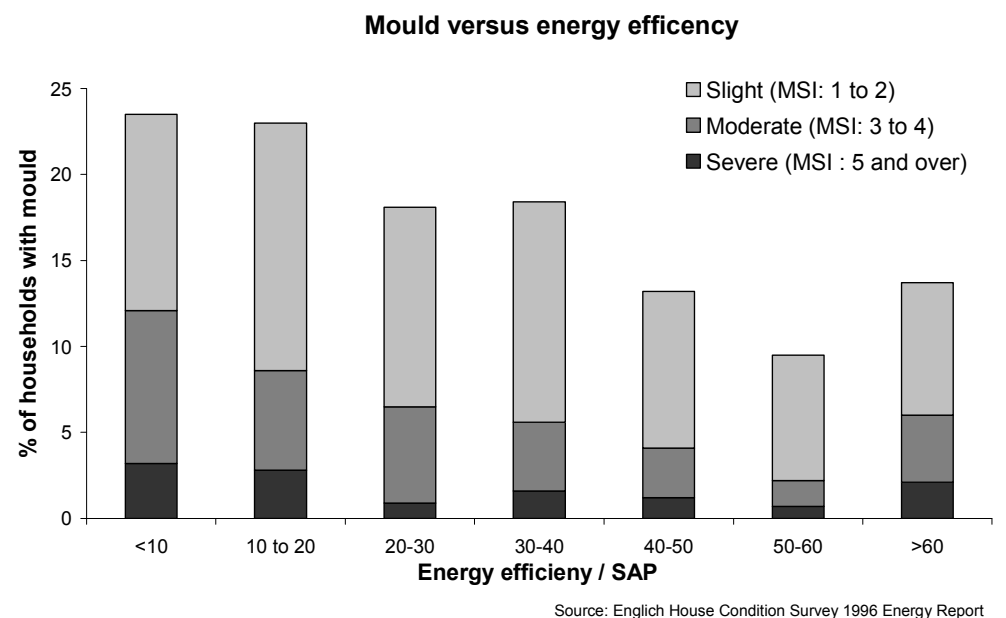

Figure A2. Vapour pressure excess vs outdoor temperature (Warm Front data)

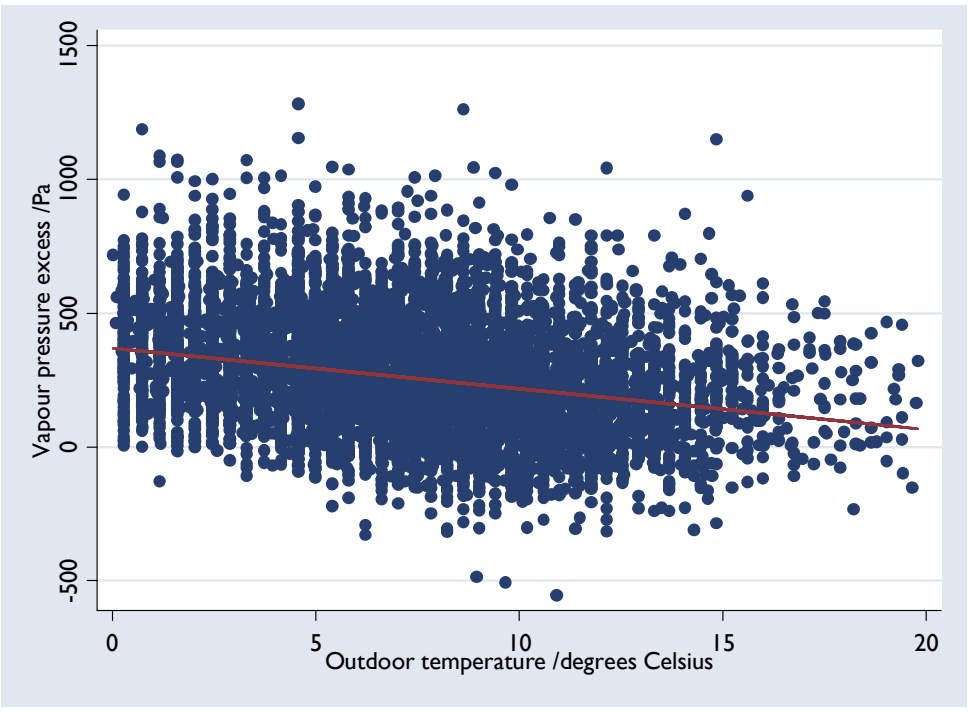

Regression equation:

vapour pressure excess $(\mathrm{Pa})=369.4-15.2 \times$ (outdoor temperature in degrees Celsius) 